\title{
Rib Spalling 3D Model for Soft Coal Seam Faces with Large Mining Height in Protective Seam Mining: Theoretical and Numerical Analyses
}

\author{
Shuai Liu, ${ }^{1,2,3}$ Ke Yang $\mathbb{D}^{2,3}$ Tong Zhang $\mathbb{D}^{2,3}$ and Chunan Tang ${ }^{1,4}$ \\ ${ }^{1}$ School of Resources and Civil Engineering, Northeastern University, Shenyang 110819, China \\ ${ }^{2}$ Institute of Energy, Hefei Comprehensive National Science Center, Hefei 230031, China \\ ${ }^{3}$ State Key Laboratory of Mining Response and Disaster Prevention and Control in Deep Coal Mines, Anhui University of Science \\ and Technology, Huainan 232001, China \\ ${ }^{4}$ School of Civil and Hydraulic Engineering, Dalian University of Technology, Dalian 116024, China
}

Correspondence should be addressed to Ke Yang; keyang2003@163.com and Tong Zhang; 1099731996@qq.com

Received 16 July 2020; Revised 18 August 2020; Accepted 23 August 2020; Published 24 September 2020

Academic Editor: Qiqing Wang

Copyright $\odot 2020$ Shuai Liu et al. This is an open access article distributed under the Creative Commons Attribution License, which permits unrestricted use, distribution, and reproduction in any medium, provided the original work is properly cited.

\begin{abstract}
Fully-mechanized mining of coal face with a large cutting height is generally jeopardized by rib spalling disaster in the working face. Preventive measures based on undisturbed coal seam conditions fail to provide safe predictions, as large-scale fractures in soft coal face frequently appear before excavation due to mining-induced stresses. This paper investigates a case study of the Paner Mine 11224 working face in the Huainan mine area, China, which features an overlying protected layer in the protective seam mining. To simulate the failure process in such a mine, we elaborated a simplified physical-mechanical model of a coal wall that underwent shear failure and sliding instability, in compliance with the triangular prism unit criterion. Similar simulation experiments, theoretical calculations, and borehole monitoring were used to comprehensively analyze the overburden fracture and movement after mining the lower protective seam. The development height of three overburden zones was determined, and the characteristics of the protected layer affected by mining were obtained. The results show that the failure is mainly related to the roof load, coal cohesion, internal friction angle, coal seam inclination, and sidewall protecting force. The key to limiting the frictional sliding of a slip body is to reduce the roof load and increase the sliding coefficient and cohesion of the main control weak surface (MCWS). Besides, a self-developed three-dimensional numerical calculation software RFPA3D (Realistic Fracture Process 3D Analysis), which considered the rock heterogeneity, was used to reproduce a weak triangular prism's progressive failure process. The numerical simulation results agreed with the fracture pattern predicted by the theoretical model, which accurately described the rib spalling mechanisms in a soft coal face with a large cutting height and a protective layer.
\end{abstract}

\section{Introduction}

Sustainable development of the coal mining industry is quite topical, especially in China, where coal remains the main energy resource [1-3]. This problem comprehensive solution requires the account of such subtopics as the development of efficient mining technology [4-6], protection of the ecological environment and groundwater [7-9], clean use of methane $[10,11]$, and prevention and control of disasters caused by coal production $[12,13]$. The primary sources of coal in China are thick continuous coal seams that account for about
$45 \%$ of the total coal resource reserve and production [14]. Longwall fully-mechanized mining and top coal caving methods are mainly used for the most efficient mining of thick coal seams $[15,16]$. When the thickness of a coal seam exceeds $3.5 \mathrm{~m}$, longwall mining with top coal caving is generally adopted, but the problems of low recovery rate and complicated technology have not been adequately resolved [17-19]. With the improvement of mining equipment and management level of working face in recent years, a stope's cutting height was gradually increased. For coal seams with a thickness of 3.5-7.5 m, coal cutting of the full height can 


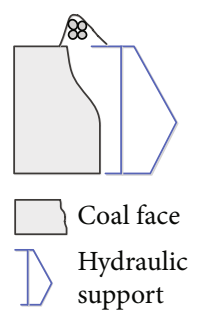

(a)

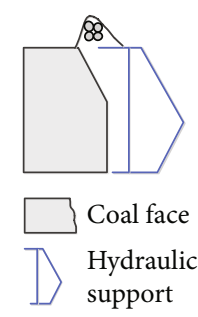

(b)

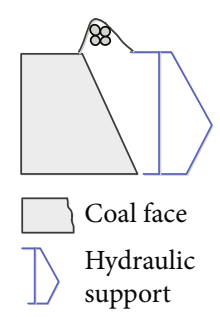

(c)

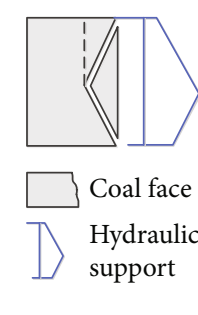

(d)

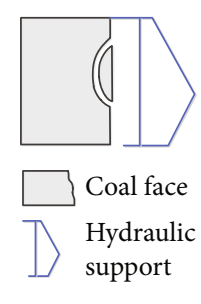

(e)

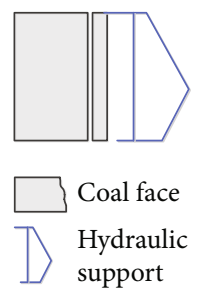

(f)

FIGURE 1: The common form of rib spalling in a working face with a large cutting height: (a-c) soft coal seam rib spalling; (d-f) hard coal seam rib spalling.

effectively overcome the above problems. However, an increase in cutting height can produce such problems as intense ground pressure, rib spalling, roof failure, support dumping, and sliding, which are hardly avoidable in the stope $[20,21]$. In particular, rib spalling is the most common disaster when the working face coal seam is thick, yet becomes soft, which is a severe safety infringement. Simultaneously, the start-up rate of mining equipment is dramatically decreased, creating a less efficient system for fully mechanized mining with large cutting height. The instability caused by rib spalling of the surrounding rock supporting the stope has become a bottleneck restricting the technology's sustainable development. It is an urgent issue that needs to be resolved for safe and efficient extraction of soft, thick coal seams.

Coal wall fractures and slips during mining are known to cause the rib spalling of the working face, but the latter's mechanism is not well understood. Several physicalmechanical models based on the fracture characteristics and rib spalling location in thick coal seams with a large cutting height have been developed [22-24]. The influence of several parameters on the coal wall's stability and further preventive and control measures has also been proposed [25]. Field observations have shown that soft coal seams are prone to arcing or linear rib spalling on the upper part of the coal wall or the working face's overall shear slip. The immediate roof fall is usually synchronized with these three forms as well (Figures 1(a)-1(c)). The instability of hard coal seams is sudden and brittle. Depending on the occurrence location, the rib spall forms grooves or horizontal overall tensile fractures throughout the wall (Figures 1(d)-1(f)).

Several theoretical models have been proposed to describe these forms of rib spalling in a coal wall. Zhang et al. [26] proposed layered plate structure models using fracture damage and elastoplastic theories. Yin et al. [27] and Ning [28] improved the coal wall's deflection characteristics by using the proposed pressure bar structure model. Yuan et al. [25] established a mechanical model of the wedgeshaped sliding body of the coal wall and analyzed vital factors affecting a wedge-shaped body's stability. Hao et al. [29] applied the stochastic analysis method for slope engineering to establish a mechanical model of coal-face slippage for sections with a large mining height. Wang [30] proposed a shear failure model for soft, thick coal seams, which found wide practical and theoretical applications. Fu et al. [31] used the unloading rock mass mechanics theory and fracture mechanics theory to establish an unloading effect model of coal wall excavation. They introduced a new instability criterion for a wedge-shaped structure. Yang et al. [32] studied the development of coal seam cracks formed during mining and analyzed coal wall instability's mechanical process using the slip line theory. Based on the unique geological background of coal mines, Wang et al. [33] proposed a coal wall rock beam model to analyze the influence of mining thickness on steep seam stability. Wu et al. [34] used the shear-slip failure criterion to establish a space stress model of the coal wall block elements in a working face. Pang et al. [35] elaborated on a tensile cracking-sliding model, which implied that it was problematic to prevent the coal wall from tensile cracking only by the force of the hydraulic support guard plate. Still, the latter could suppress the damaged body's sliding. Liu et al. [36] monitored the damage process in coal walls with a large mining height using the smart control system, which was found very effective. Chang et al. [37] used the MohrCoulomb criterion to derive the analytical expressions of coal wall horizontal displacement, fracture zone, and plastic zone radius. They also reported that the abutment pressure concentration factor, cutting height, and support resistance of support were the key factors controlling the rib spalling. Song et al. [38] used the Ritz method based on the displacement variation principle to analyze the coal wall failure mechanism and used a three-dimensional similarity simulation platform to study the coordinated deformation law of the "roofsupport-coal wall" system.

The above research results have significantly improved the understanding of coal wall fracture and slip. However, most researchers reduced the coal wall instability problem to a plane strain problem when establishing the mechanical model of rib spalling. This approach is not suitable for some cases with complex three-dimensional failure characteristics. Moreover, the obtained failure mechanical models were mostly based on coal seam mining in its original state. Rib spalling in coal seams that have been disturbed by mining stress and have large-scale mining fractures before extracting are rarely studied. For gas outburst coal seams with low permeability, the protective-layer mining is the most effective method for regional elimination of gas outbursts hazards in protected coal seams [11]. The coal seams within a specific range of the top and bottom layers of the protective layer are depressurized to form mining cracks through the mining operation. This allows for increased permeability and degassing of the protected coal seam by pumping the methane out of the coal seam in advance [10]. Yet, this damages the 


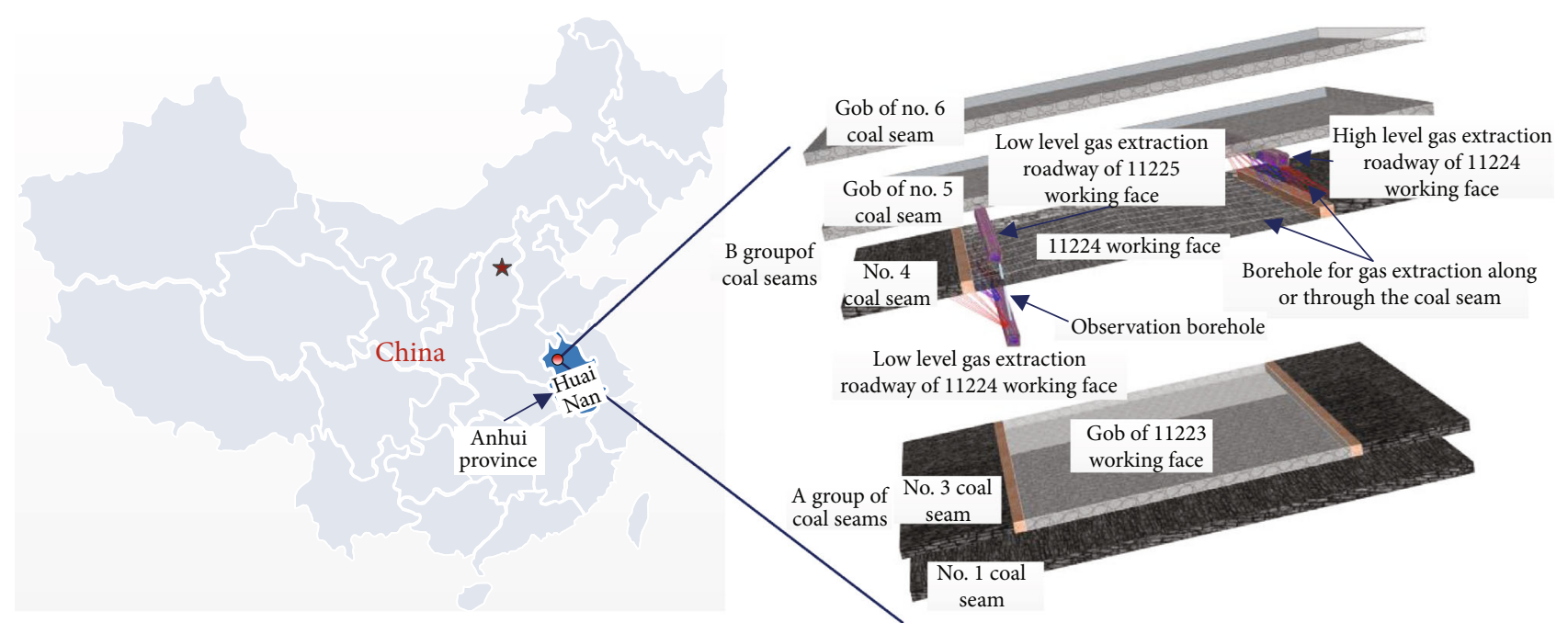

Figure 2: Distribution of the protective layer \#3 coal seam and protected layer \# 4 coal seam.

integrity of coal rock mass before normal mining occurs. Further research is needed to determine failure, slip, and rib spalling in a large-height cutting face of protected coal seam. This would allow for the adoption of engineering measures to prevent and control rib spalling and improve the efficiency of fully mechanized mining face.

In this study, a simplified physical-mechanical model of a remote lower protective layer mining is established to determine the range of influence and coal wall instability during the protective-layer mining. This model includes overburden fracturing and movement based on simulation, theoretical analysis, and field measurements to improve model accuracy. The range of three vertical zones (caving zone, fracture zone, and bending-and-sinking zone) affected during protective mining was determined to model the range of influence of the protective mining under various conditions. Selfdeveloped RFPA3D numerical calculation software was then used to simulate a large-height mining soft coal face's load instability to verify the proposed physical-mechanical model. The research results can guide the development of prevention and control measures, as well as ensure safe and efficient mining of a fully mechanized working face of a large-height, soft coal wall.

\section{Project Overview}

The case study mine is the Paner Coal Mine, located in the Huainan mine area, China, an important coal and electricity production base in eastern China. There are two coal seam strata groups in the mining area, $\mathrm{A}$ and $\mathrm{B}$, with an inclination (dip angle) from 15 to $30^{\circ}$. Group A coal stratum is located in the lower part of group B coal strata with a thickness of 75$90 \mathrm{~m}$. Seams \#1 and \#3 are mainly mined from the group A coal, while coal seams \#4, \#5, and \#6 are mainly mined from group B coal. The test working face for this research is the first working face of coal seam \#4, also called working face 11224. Working face 11224 has a burial depth of about $700 \mathrm{~m}$ and an average thickness of $3.5 \mathrm{~m}$. Longwall fully mechanized mining with a large cutting height is currently used to extract the working face. There is a high risk of coal and gas outburst of the coal seam \#4, as it has a gas content of $12.5 \mathrm{~m}^{3} / \mathrm{t}$ and a gas pressure of $2.9 \mathrm{MPa}$. The recovery of \#5 and \#6 coal seams has been completed. \#5 coal goaf is about $25 \mathrm{~m}$ away from \#4 coal seam. Numerical analysis and on-site observations have shown that mining of \#6 and \#5 coal seams has not affected \#4 coal seam. The research results have been published [39].

About $80 \mathrm{~m}$ of the \#4 coal floor is the \#3 coal, and the gas pressure and content are relatively low in the seam. A lower protective layer is also implemented during mining to eliminate the \#4 coal seams outburst danger. The working face 11223 of the \#3 coal is first mined, and pregas extraction is performed after the \#4 coal pressure relief. The position of the two working faces is shown in Figure 2.

The stratigraphy and coal rock mass mechanical parameters of \#3 and 4 coal seams were obtained through field coring and laboratory mechanical tests, as shown in Figure 3.

During the lower protective layer's mining process, the pregas extraction of the 11224 working face of the protected coal seam is exceedingly successful. The pressure and content of gas outburst coal seam were significantly reduced. During normal mining of the 11224 working face, the stope's surrounding rock integrity was poor, and rib spalling frequently occurred at varying degrees. Concurrently, the immediate roof fall of working face severely restricted the safe and efficient mining of the stope. Field observations found that rib spalling on the 11224 working face had complicated spatial rupture patterns. The rib spall traces are shown in Figure 4.

It can be seen from Figure 4 that rib spalling occurs in the upper part of the coal wall, area (1) in Figure 1, and the exfoliated coal body is an irregular triangular prism. A top surface of this triangular prism is the coal seams top surface, and the side surface is almost parallel to the coal seam normal. At the same time, macrocracks penetrating the coal seam were observed in the traces. After rib spalling occurred in area (1), the coal body in areas (2) and (3) was fractured and slipped. The exfoliated coal is also an irregular triangular prism, but its shape and volume are significantly different. Generally, 


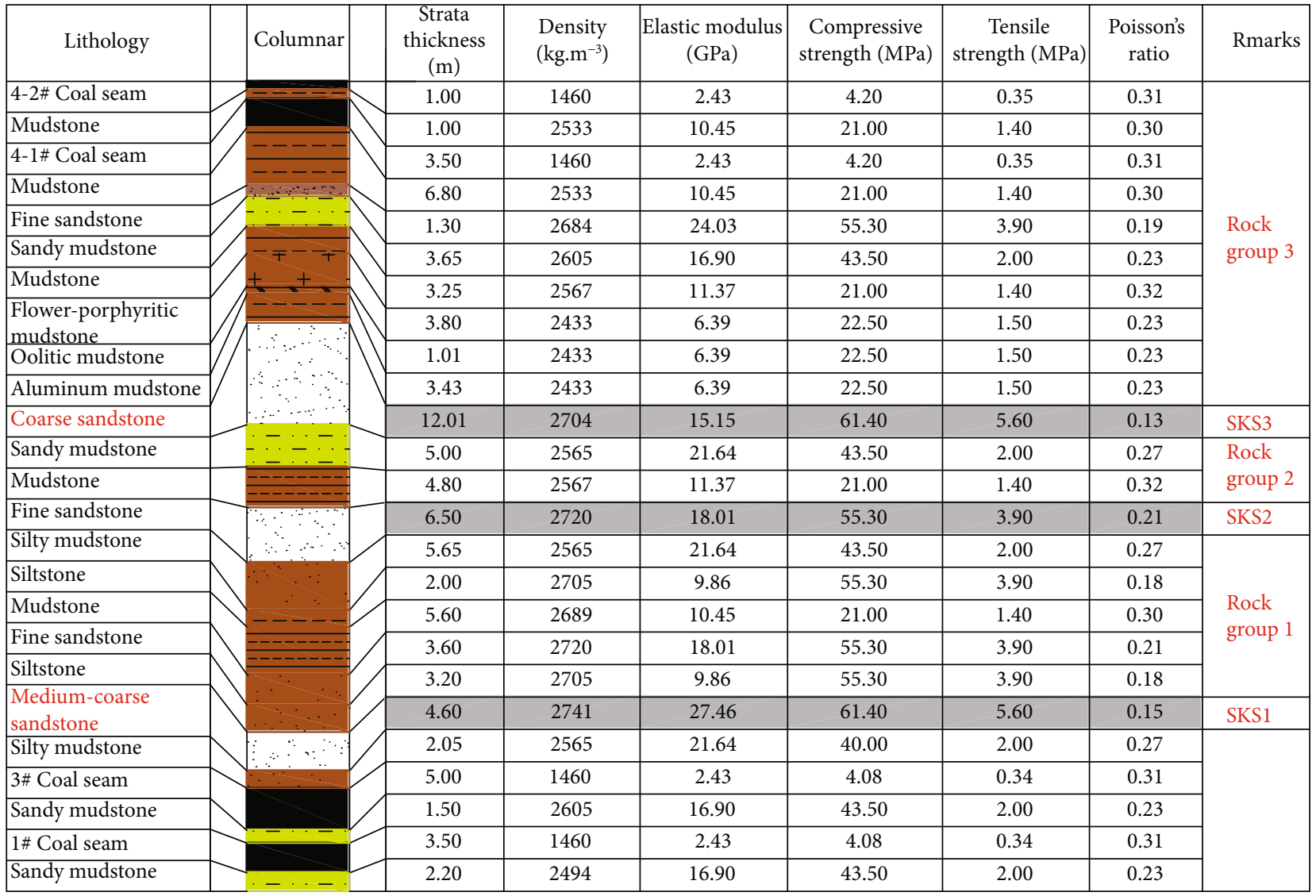

FIgURE 3: Stratigraphic column mechanical parameters of the strata between \#3 and \#4 coal seams.

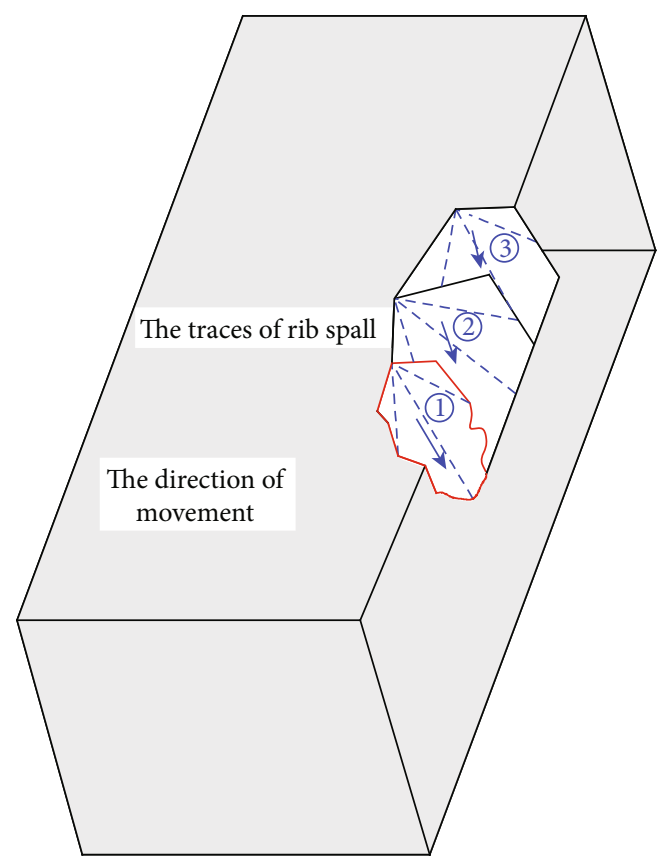

FIGURE 4: Rib spalling traces of the coal wall.

the rib spalling shape is relatively uniform in the same working face (Figure 1). The coal wall instability with a complex spatial rupture shape, such as 11224 working face, cannot be reduced to the plane strain problem when establishing a mechanical model.

\section{Mining Effects on the Protected Coal Seam}

Pregas extraction of the protected layer was successful, indicating that the lower protective layer's exploitation changed the stress environment and the fracture distribution characteristics from the initial state of the 11224 working face. Therefore, it is necessary to study the disturbance effect of mining the 11223 working face on the \#4 coal seam. The principal analysis distinguishes three vertical zones in the overburden of the protective layer's mined-out area after mining, because the overlying protected layer is located in a different spatial zone and has different degrees of disturbance and damage.

The key strata theory proposed by Qian et al. [40] implied that the structures of the region and key strata are the main factors determining the overlying strata's spatial structure above the goaf and the development height of these three zones of mining fractures. The key strata judgment theory proposed by Qian et al. [40] and Qu et al. [41] was used in this study to verify the presence of three subkey strata (SKS) between the \#3 and \#4 coal seams (Figure 3). Relatively weak rock layers controlled by each SKS belong to the same rock group, which moves synchronously with the corresponding SKS breaking. 
TABLE 1: The proportions of materials to simulate various lithologies available between the two working faces.

\begin{tabular}{lcccc}
\hline \multirow{2}{*}{ Lithology } & \multicolumn{4}{c}{ Weight proportion } \\
& Fine river sand & Lime & Gypsum & Water \\
\hline Coal & 10 & 0.5 & 0.5 & 1.1 \\
Mudstone & 10 & 0.7 & 0.3 & 1.1 \\
Fine sandstone & 6 & 0.6 & 0.4 & 0.7 \\
Sandy mudstone & 7 & 0.7 & 0.3 & 0.8 \\
Coarse sandstone & 8 & 0.6 & 0.4 & 0.9 \\
Siltstone & 9 & 0.5 & 0.5 & 1.0 \\
\hline
\end{tabular}

\subsection{Similar Simulation Test}

3.1.1. The Simulation Scheme. Based on strata structural characteristics between \#3 and \#4 coal seams, a selfdeveloped test device capable of bidirectional unequal pressure loading was used to simulate the inclined mining process of the 11223 working face. The size of the simulation platform was $2.4 \mathrm{~m} \times 0.2 \mathrm{~m} \times 2.0 \mathrm{~m}$ (length $\times$ width $\times$ height). In the test, fine river sand was used as aggregate and mixed with gypsum and lime as cement. Water was used as a binder, and mica was sprayed to simulate native layering. The preparation of similar materials and the establishment of physical models are not the focus of this article. Due to space limitations, the details can be found elsewhere, e.g., Ghabraie et al. [42]. The proportions of materials to simulate various lithologies are shown in Table 1, and the curing time of each material in the simulating test is about 15 days. The similar stress ratio was $1: 160$, and the simulated geometric and strength ratio was $1: 100$. The model's bottom surface was fixed, while the top surface and side surface were subjected to constant normal stress, respectively. A load of $0.096 \mathrm{MPa}$ was applied to the physical model top to simulate the overburden weight. The lateral pressure coefficient was 1.442 , so $0.138 \mathrm{MPa}$ was applied in the horizontal direction. The artificial excavation was used to simulate the 11223 working face mining.

3.1.2. Similar Simulation Results. Figure 5 shows the characteristics of overburden mining-induced fractures after the extraction of the 11223 working face. After mining the 11223 working face, SKS1 and its controlling rock group 1 collapsed together and slipped towards the lower part of the mined-out area. Mining layer separation developed along the bottom of SKS2, and the caving zone stopped here. Subsequently, stratum fractures developed in the upper and middle sections of SKS2. With the rupture of SKS2, the fracture and movement occurred continuously in the controlling rock group 2. However, due to the limited collapse space, no new separation between layers appeared at the bottom of SKS3, and the development of the fracture zone stopped at the bottom of SKS3. The \#4 coal seam is a synchronous moving layer controlled by SKS3. After mining, rock group 3 was located in the gob bending-and-sinking zone. Rock movement in the bending-and-sinking zone still maintained continuity and integrity. The amount of subsidence and deformation of each section of this zone was small in the vertical section.

The physical simulation also found that many macrocracks in the normal direction appeared in the \#4 coal seam and the surrounding area. The cracks' spatial location and scale were disordered, as shown in areas (a) and (b) in Figure 5. After mining the lower protective layer, the initial state of the \#4 coal seam was broken. Normal direction fractures violated the integrity of the \#4 coal with random distribution.

\subsection{The Theoretical Basis of Height Calculation of Fracture} Zones. Previous research results on the three zones of overburden's development height are mostly reduced to empirical formulas derived via statistical processing. Still, the calculation results do not typically embody actual measurements. $\mathrm{Xu}$ et al. [43] assumed that the primary key stratum's spatial position could be based on similar simulation results and field measurements to determine the fracture zone's height. However, this model failed to consider multiple SKS in the overburden during deep mining. For deep mining, Yang et al. [44] used the key stratum theory to treat each subkey stratum as a thin sloping plate fixed around a central position. A calculation model of the three-overburden zones' development height was elaborated by analyzing the breaking conditions of subkey strata. According to this model, the three zones' development status in the overlying strata above the stope was determined by key strata structure, mining height, and rock expansion coefficient. Assuming the stope mining thickness of $m$ (i.e., full thickness of the coal seam), $n$ rock layers under a certain SKS, the thickness of each rock layer of $H_{i}$, and the corresponding fracture expansion coefficient of $r_{i}$, the SKS breaking conditions would be as follows:

$$
m-H_{1}\left(r_{1}-1\right)-\sum_{i}^{n} H_{i}\left(r_{i}-1\right)>0 .
$$

If rock stratum below SKS1 satisfies formula (1) when SKS1 reaches its limit span, it breaks, and the fracture zone develops to the bottom of SKS2. Then, if the rock stratum below SKS2 satisfies formula (1) when SKS2 reaches its limit span, it breaks, and the fracture zone continues to develop to the bottom of SKS3. Until the rock strata below the SKS fails to satisfy formula (1), the fracture zone height ends at the bottom of the first unbroken SKS.

\subsection{Borehole Monitoring}

3.3.1. The Monitoring Scheme. On-site monitoring is the most intuitive and reliable method to study layer fractures and movement. The low-level gas extraction roadway of the 11224 working face is located in SKS3, $25 \mathrm{~m}$ away from the \#4 coal seam. The low-level gas extraction roadway of the 11225 working face is located $21 \mathrm{~m}$ above the \#4 coal roof and is a predraining roadway for the \#5 coal seam. The horizontal distance between the two roadways is $13 \mathrm{~m}$. A monitoring borehole was placed at an inclined slope of $75^{\circ}$ in the 11224 low-level gas extraction roadway roof. The observation 


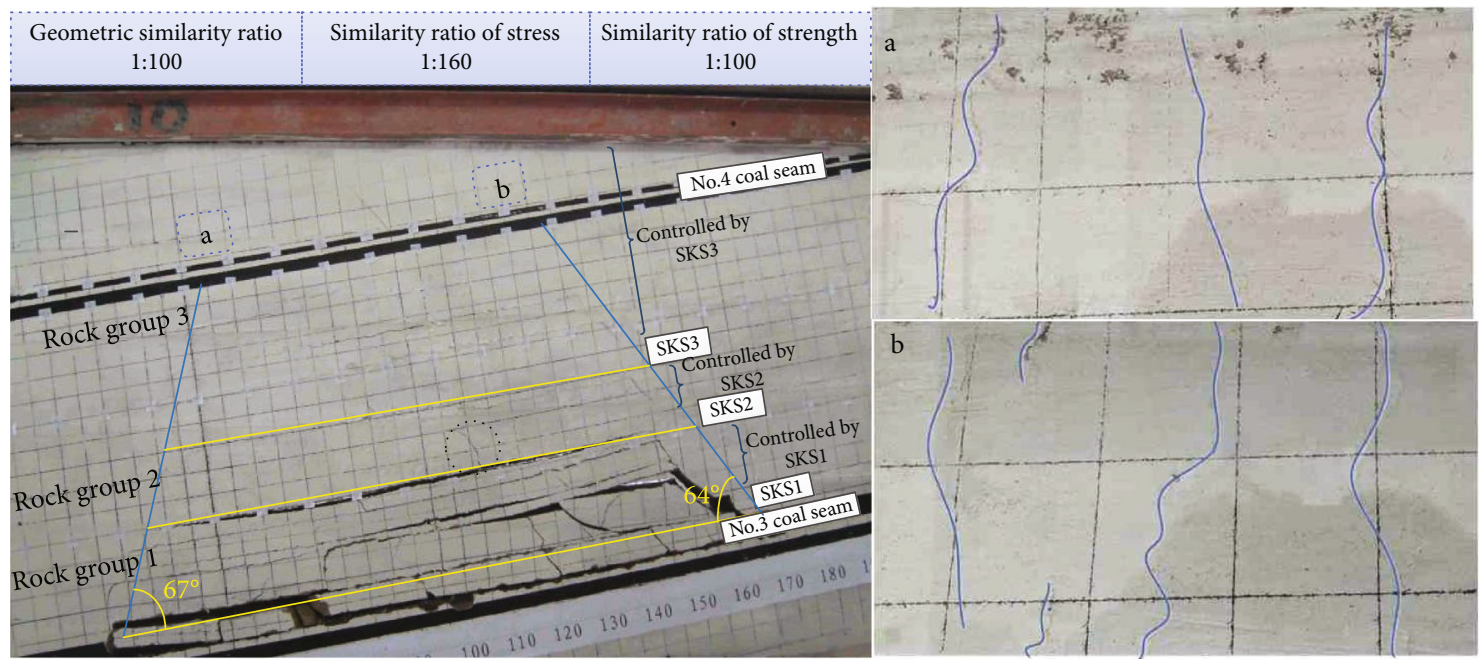

FIGURE 5: Development characteristics of fractures in the overlying strata during mining of the lower protective \#3 coal seam.

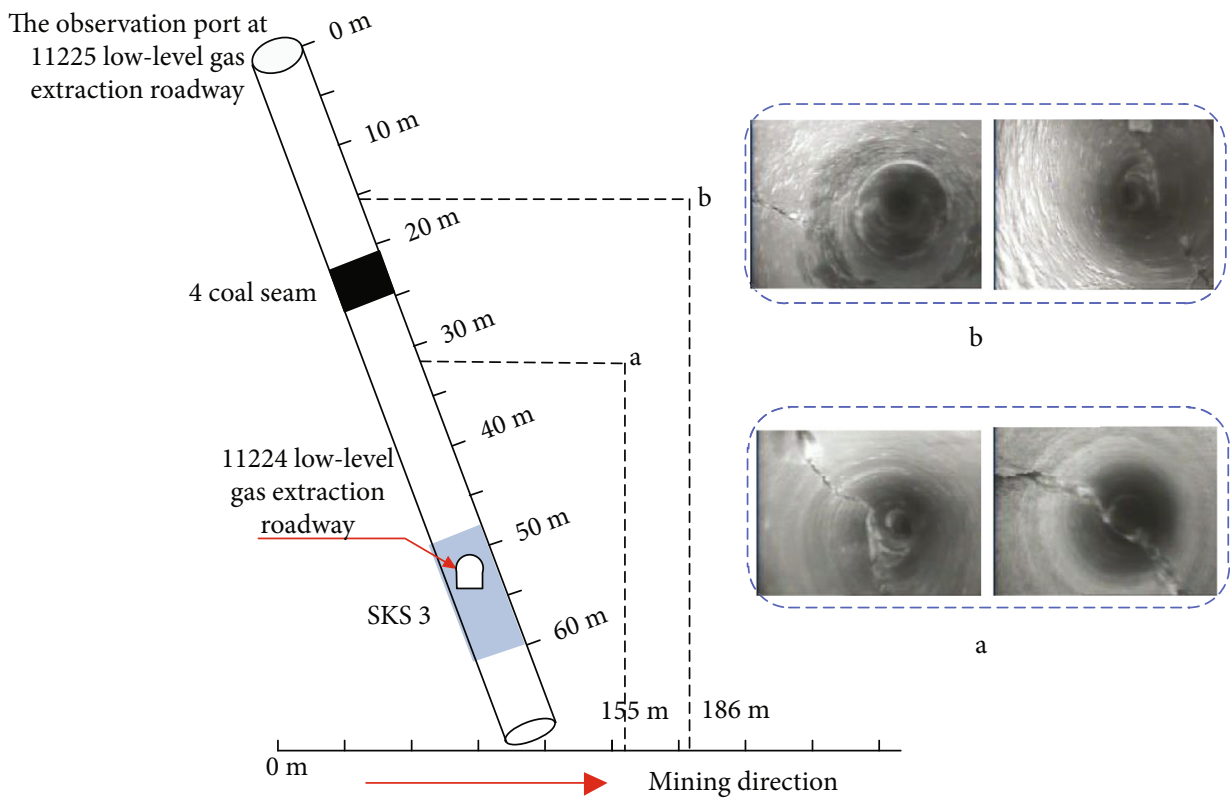

FIGURE 6: Observation results of borehole monitoring during the mining of 11223 working face. (a) Vertical cracks penetrating the layer at a depth of $32 \mathrm{~m}$; (b) Vertical cracks formed at a depth of $16 \mathrm{~m}$.

port is located at the bottom of the 11225 low-level gas extraction roadway. The borehole spatial position is shown in Figure 2. To monitor the protected seams disturbing characteristics after mining the 11223 working face, a rock drilling detector was used to observe the borehole wall's deformation.

3.3.2. The Monitoring Results. The observation results are shown in Figure 6. When 11223 working face passed the observation port $155 \mathrm{~m}$, vertical cracks penetrating the rock layers were observed at a depth of $32 \mathrm{~m}$, as shown in Figure 6(a). When working face passed observation port $186 \mathrm{~m}$, \#4 coal seam collapsed and blocked the borehole. Vertical cracks were also observed at a depth of $16 \mathrm{~m}$, as shown in Figure 6(b). During the mining of 11223 working face, no layer separation was monitored in the borehole, indicating that SKS3 did not break. However, vertical fractures were widely observed. Therefore, the disturbed rock layers around \#4 coal seam were located in the overburden bending-andsinking zone. Fractures paralleled to the borehole appeared in the protected coal seams vicinity, which was consistent with physical simulation results. Simultaneously, macronormal penetrating fractures were more intuitively observed during the mining of 11224 working face, as shown in Figure 7.

3.4. Comprehensive Analysis. Similar simulations show that after mining the 11223 working face, the fracture zone that transmits water ceases at the bottom of SKS3. Also, the \#4 coal protected layer was located in a bending-and-sinking 


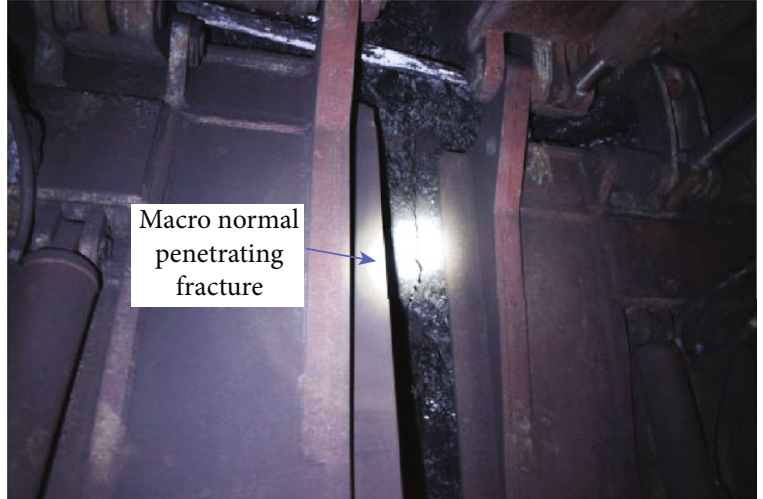

FIGURE 7: Macronormal penetrating fracture in the 11224 working face.

overburden zone. However, due to the test rig's limited size in the indoor physical simulation experiment, limit spans of key stratum may not be reached. Therefore, it is not possible to accurately determine the development status of the three overburden zones simply based on the experimental results.

Equation (1) is the SKS breaking criterion obtained based on the thin plate theory [45]. Given the lack of measured data on the layer expansion coefficient in the overburden of the 11223 goaf, Hao [46] results on the Yangquan Coal Mine with similar geological conditions were used in this study.

$$
r=1.083-0.017 \cdot \ln (h) \quad h<100 m,
$$

where $r$ is the rock expansion coefficient, and $h$ represents the vertical distance from the coal seam.

Based on the measured expansion coefficient of rock layers and values from the Yangquan Coal Mine, it was calculated that only SK1 and SKS2 fractures occurred in the overburden of the 11223 working face, and the fracture zone stopped at the base of SKS3. The weak rock penetration controlled by SKS3 was located in the bending-and-sinking zone, including the \#4 coal seam. Borehole monitoring observed mining fractures near the \#4 coal, but no layer separation occurred. It was inferred that SKS3 did not fracture after extracting the 11223 stope. Similar simulations, theoretical analysis, and borehole monitoring conclusions are consistent. All results reflect that the \#4 coal protected layer is located in the bending-and-sinking overburden zone. Coal and rock layers in the bending-and-sinking zone are typically less affected by mining the lower protective layer, and no large-scale severe mining damage occurs.

Macrocracks along the normal direction of rock layers appeared in the area near the \# 4 coal seam, and they were also all observed in similar simulation and borehole monitoring. This phenomenon was also seen during normal mining of the 11224 working face. It shows that the protective layer \#3 coal mining affected the original rock state of the protected layer \#4 coal located in the bending-and-sinking zone; the \#4 coal was not seriously fractured. The coal rock mass, which had good integrity before mining, was intersected by randomly distributed fractures.

\section{A Mechanical Model for Rib Spalling of Protected Coal Seam}

4.1. Physical Mechanics Model. The previous analysis shows that the 11224 working face is affected by the mining of the lower protective layer even though it is located in the continuous bending overburden zone. Even in this zone, there were already several randomly distributed normal-direction fractures before mining began. Affected by the advanced abutment pressure, the coal wall properties gradually deteriorated during the mining process. The normal direction fractures in the coal body in front of the working face continued to develop and penetrate due to the increasing abutment pressure, thus forming weak joint faces of different sizes [47]. The existence of joint cracks and a weak surface dramatically reduces the coal body's integrity and increases the difficulty in controlling the coal wall's stability [48].

The study here suggests that the weak surface that is the largest and has a main mechanical control role is the main control weak surface (MCWS) among the joint cracks. The MCWS divides a coal body adjacent to the working face into units and has weak mechanical bonds with the surrounding coal bodies. Due to the coal body's roof pressure and weight, the soft coal unit undergoes shear failure to a certain height and direction to form a slip body. When the surrounding unit fails to restrict the slipping body's sliding along the weak surface, rib spalling forms. Due to the randomness of the MCWS distribution, the morphology of the unit body is different. The unit on the side of the coal wall facing the air can be reduced to a triangular prism by determining the MCWS, as shown in Figure 8 .

Based on the above simplification, a three-dimensional mechanical model of coal wall instability in the protected large-cutting height soft coal working face, as shown in Figure 8, is established. The intersection of MCWS abcd and MCWS $b f e c$ formed by mining operation creates the triangular prism abfdce with a weak mechanical bond with the surrounding coal bodies. The shear failure criterion of a triangular prismatic unit with an arbitrary shape and the sliding criterion of the slip body are proposed based on the Mohr-Coulomb criterion. Most of the actual shear slips are curved surfaces. Due to the limited height of the coal wall and rib spalling, the fracture surface is treated as a plane for strength analysis convenience.

4.2. Shear Failure Criterion of Unit. Triangular prism abfdce undergoes shear failure along MCWS abcd and MCWS bfec due to the roof pressure, gravity, sidewall protecting force, and the surrounding unit confining pressure. The shear fracture traces $b a^{\prime}$ and $b f^{\prime}$ are formed, respectively, and the surface $b a^{\prime} f^{\prime}$ formed by the intersection of the two traces is the unit fracture surface. The sidewall protecting force provided by hydraulic support is $P_{\mathrm{h}}$, and the confining pressure of the surrounding unit on MCWS abcd and MCWS bfec can be derived as:

$$
P_{\mathrm{w}}=P_{\mathrm{v}} \cdot v /(1-v)
$$

Where $P_{\mathrm{w}}$ is the normal stress on MCWS, $P_{\mathrm{v}}$ is the combined force of the roof load and vertical component of gravity along MCWS, and $v$ is Poisson's ratio of a coal body. It is 


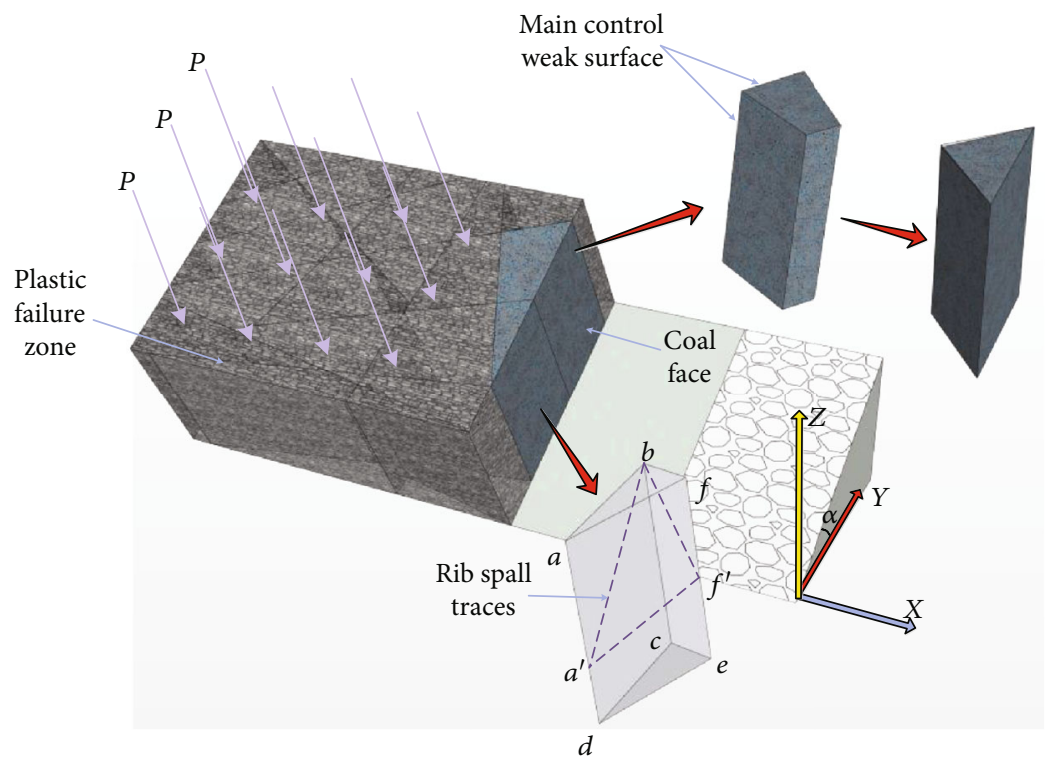

FIGURE 8: Physical-mechanical model of coal wall failure in a protected soft coal seam with large cutting height. $P$ is the normal load on the coal wall, and $\alpha$ is the inclination of the coal seam (dip angle).

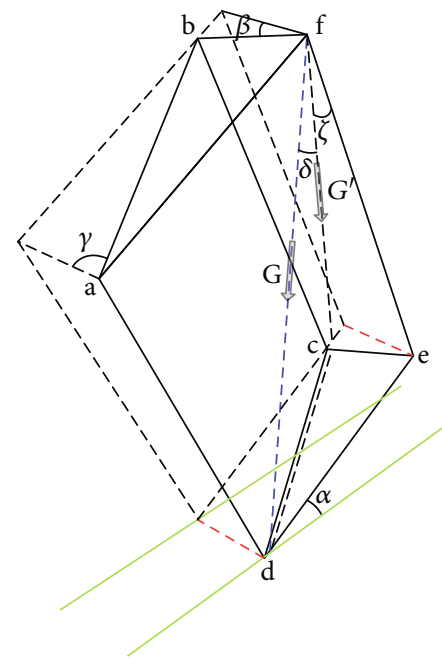

(a)

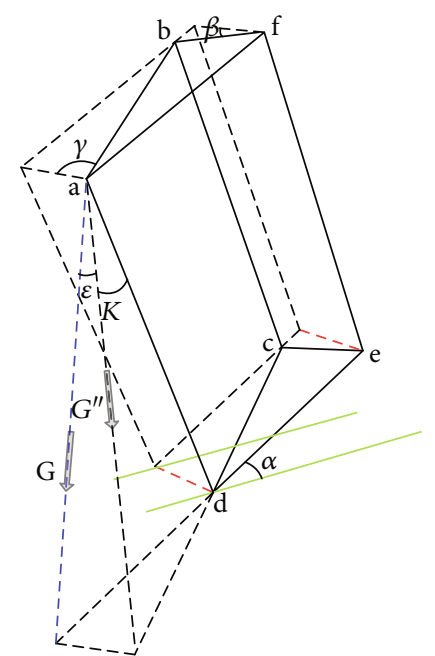

(b)

FIGURE 9: The component of gravity on MCWS. (a) The component of gravity on MCWS bfec. (b) The component of gravity on MCWS abcd.

assumed that $P_{\mathrm{h}}<P_{\mathrm{w}}<P_{\mathrm{v}}$. When applying the MohrCoulomb criterion to the strength analysis of a triangular prism, the intermediate principal stress $P_{\mathrm{w}}$ is not considered, and its fracture surface is parallel to $P_{\mathrm{w}}$.
Figure 9 depicts the spatial components of gravity of the coal body on the two MCWS of the triangular prism. From the spatial geometric relationship in Figure 9, we can obtain:

$$
\begin{aligned}
& \cos \delta=\sqrt{1-\sin \alpha^{2} \cos \beta^{2}} \quad G^{\prime}=G \cos \delta \quad \sin \zeta=\frac{\sin \beta \tan \alpha}{\sqrt{1+\sin ^{2} \beta \tan ^{2} \alpha}} \quad \cos \zeta=\frac{1}{\sqrt{1+\sin ^{2} \beta \tan ^{2} \alpha}}, \\
& \cos \varepsilon=\sqrt{1-\sin \alpha^{2} \cos \gamma^{2}} \quad G^{\prime \prime}=G \cos \varepsilon \quad \sin \kappa=\frac{\sin \gamma \tan \alpha}{\sqrt{1+\sin ^{2} \gamma \tan ^{2} \alpha}} \quad \cos \kappa=\frac{1}{\sqrt{1+\sin ^{2} \gamma \tan ^{2} \alpha}} \text {. }
\end{aligned}
$$




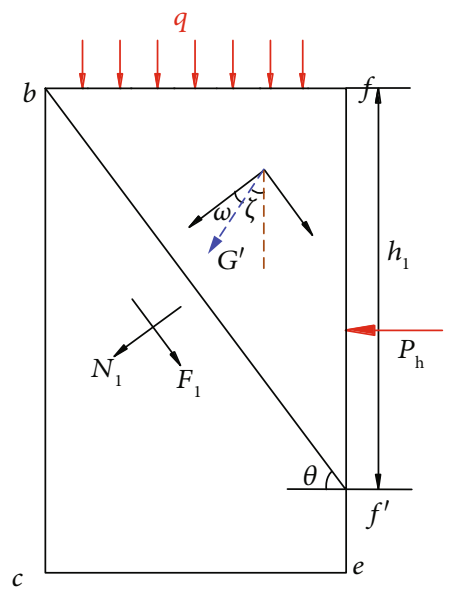

(a)

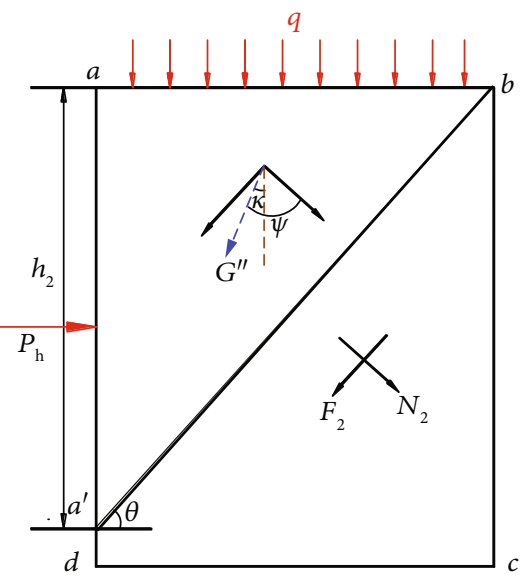

(b)

FIgUre 10: Analysis of shear failure of MCWS. (a) MCWS bfec. (b) MCWS abcd.

Here, $G$ is the gravity of the coal wall slip body, $G^{\prime}$ is the component of $G$ on MCWS bfec, and $G^{\prime \prime}$ is the component of $G$ on MCWS $a b c d ; \beta$ and $\gamma$ are the angles between MCWS $b f e c$, MCWS $a b c d$, and the coal seam strike, respectively, and are random; $\delta$ and $\varepsilon$ are the angles between the direction of $G$, MCWS $b f e c$, and MCWS $a b c d$, respectively; $\zeta$ and $\kappa$ are the angles between the component of $G$ on the MCWS $b f e c$, MCWS $a b c d$, and the coal wall.

According to the Mohr-Coulomb strength theory, the failure criterion of MCWS bfec and MCWS abcd can be expressed as the difference between the sliding force $F$ along the shear plane and the shear resistance force $D$. If the difference is greater than 0 , shear failure occurs in the triangular prism unit:

$$
W=F-D \geq 0 .
$$

Figure 10 depicts a schematic diagram of the shear fracture of MCWS, where $\theta$ is the angle between the shear plane and the coal wall; $q$ is the load concentration of the roof, and $N$ is the normal stress on the shear plane. $h_{1}$ is the shear failure height of MCWS bfec; $N_{1}$ is the normal stress on the MCWS $b f e c$ shear surface; $F_{1}$ is the sliding force on the shear plane of MCWS bfec; $h_{2}$ is the shear failure height of MCWS $a b c d$; $\mathrm{N}_{2}$ is the normal stress on the MCWS abcd shear surface; $F_{2}$ is the sliding force on the shear plane of MCWS abcd.

From the geometric relationship of the components in Figure 10(a), we can obtain:

$$
\begin{aligned}
P_{1} & =q h_{1} \cot \theta, \\
\omega & =\theta-\zeta, \\
N_{1} & =P_{1} \cos \theta+G^{\prime} \cos \omega+P_{h} h_{1} \sin \theta .
\end{aligned}
$$

Assuming that the width of the sliding surface is $1 \mathrm{~m}$, the sliding force and shear resistance force are the following, respectively:

$$
\begin{aligned}
& F_{1}=P_{1} \sin \theta+G^{\prime} \sin \omega+P_{h} h_{1} \cos \theta, \\
& D_{1}=C h_{1} \csc \theta+N_{1} \tan \varphi,
\end{aligned}
$$

where $C$ is the cohesion of coal, and $\varphi$ is the internal friction angle.

The substitution of Eq. (9) into Eq. (11) gives:

$D_{1}=C h_{1} \csc \theta+\left(P_{1} \cos \theta+G^{\prime} \cos \omega+P_{h} h_{1} \sin \theta\right) \tan \varphi$.

After substituting Eq. (10) and (12) into Eq. (6), $W_{1}$ can be defined as:

$$
\begin{aligned}
W_{1}= & P_{1} \sin \theta+G^{\prime} \sin \omega-P_{h} \cos \theta-C h_{1} \csc \theta \\
& -\left(P_{1} \cos \theta+G^{\prime} \cos \omega+P_{h} h_{1} \sin \theta\right) \tan \varphi .
\end{aligned}
$$

Substituting Eq. (4), (7), and (8) into Eq. (13) gives:

$$
\begin{aligned}
W_{1}= & q h_{1} \cot \theta(\sin \theta-\cos \theta \tan \varphi) \\
& -C h_{1} \csc \theta+G \sqrt{1-\sin \alpha^{2} \cos \beta^{2}} \\
& \times\left((\sin \theta-\cos \theta \sin \beta \tan \alpha) /\left(\sqrt{1+\sin ^{2} \beta \tan ^{2} \alpha}\right)\right. \\
& \left.-(\cos \theta+\sin \theta \sin \beta \tan \alpha) \tan \varphi /\left(\sqrt{1+\sin ^{2} \beta \tan ^{2} \alpha}\right)\right) \\
& -P_{h}(\cos \theta+\sin \theta \tan \varphi) .
\end{aligned}
$$

Similarly, from Figure 10(b):

$$
\begin{gathered}
P_{2}=q h_{2} \cot \theta, \\
\psi=\theta+\kappa,
\end{gathered}
$$

$N_{2}=P_{2} \cos \theta+G^{\prime \prime} \cos \psi+P_{h} h_{2} \sin \theta$,

$D_{2}=C h_{2} \csc \theta+\left(P_{2} \cos \theta+G^{\prime \prime} \cos \psi+P_{h} h_{2} \sin \theta\right) \tan \varphi$,

$F_{2}=P_{2} \sin \theta+G^{\prime \prime} \sin \psi+P_{h} h_{2} \cos \theta$. 
By substituting Eq. (18) and (19) into Eq. (6), $W_{2}$ is expressed as:

$$
\begin{aligned}
W_{2}= & P_{2} \sin \theta+G^{\prime \prime} \sin \psi-P_{h} \cos \theta-C h_{2} \csc \theta \\
& -\left(P_{2} \cos \theta+G^{\prime \prime} \cos \psi+P_{h} \sin \theta\right) \tan \varphi
\end{aligned}
$$

Substituting Eq. (5), (15) and (16) into Eq. (20) gives:

$$
\begin{aligned}
W_{2}= & q h_{2} \cot \theta(\sin \theta-\cos \theta \tan \varphi) \\
& -C h_{2} \csc \theta+G \sqrt{1-\sin \alpha^{2} \cos \gamma^{2}} \\
& \times\left((\sin \theta+\cos \theta \sin \gamma \tan \alpha) /\left(\sqrt{1+\sin ^{2} \gamma \tan ^{2} \alpha}\right)\right. \\
& -(\cos \theta-\sin \theta \sin \gamma \tan \alpha) \tan \psi /\left(\sqrt{1+\sin ^{2} \gamma \tan ^{2} \alpha}\right) \\
& -P_{h}(\cos \theta+\sin \theta \tan \varphi) .
\end{aligned}
$$

When both $W_{1}$ and $W_{2}$ exceed zero, the triangular prism abfdce undergoes shear failure along the surface $b a^{\prime} f^{\prime}$ to form a slip body. Equation (22) is the shear failure criterion of the coal wall unit considering the confining pressure:

$$
\left\{\begin{array}{l}
q h_{1} \cot \theta(\sin \theta-\cos \theta \tan \varphi)-C h_{1} \csc \theta+G \sqrt{1-\sin \alpha^{2} \cos \beta^{2}} \\
\times\left(\frac{\sin \theta-\cos \theta \sin \beta \tan \alpha}{\sqrt{1+\sin ^{2} \beta \tan ^{2} \alpha}}-\frac{\cos \theta+\sin \theta \sin \beta \tan \alpha}{\sqrt{1+\sin ^{2} \beta \tan ^{2} \alpha}} \tan \varphi\right) \\
-P_{h}(\cos \theta+\sin \theta \tan \varphi) \geq 0 \\
q h_{2} \cot \theta(\sin \theta-\cos \theta \tan \varphi)-C h_{2} \csc \theta+G \sqrt{1-\sin \alpha^{2} \cos \gamma^{2}} \\
\times\left(\frac{\sin \theta-\cos \theta \sin \gamma \tan \alpha}{\sqrt{1+\sin ^{2} \gamma \tan ^{2} \alpha}}-\frac{\cos \theta+\sin \theta \sin \gamma \tan \alpha}{\sqrt{1+\sin ^{2} \gamma \tan ^{2} \alpha}} \tan \varphi\right) \\
-P_{h}(\cos \theta+\sin \theta \tan \varphi) \geq 0
\end{array} .\right.
$$

In Eq. (22), which determines the unit spatial shape, $G, h_{1}$, $h_{2}, \beta, \gamma$, and $\theta$ are constant values. Therefore, shear failure in the unit is mainly related to the roof load $q$, coal cohesion $C$, internal friction angle $\varphi$, coal seam inclination $\alpha$, and sidewall protecting force $P_{h}$. Prevention and control of rib spalling should start by reducing the roof load and increasing coal cohesion, the internal friction angle, and the sidewall protecting force. Increasing the inclination of the coal seam can reduce the influence of gravity and roof pressure in the coal seam normal direction, but increases the difficulty of antifall and antislip control of the hydraulic support.

4.3. The Sliding Criterion of the Slip Body. A slip body forms after triangular prism shear failure. When the MCWS and protection measures are not sufficient to restrict the sliding of a slip body, it will slip along the fracture surface $b a^{\prime} f^{\prime}$ to form a rib spall. Rib spalling often occurs during coal cutting and support removal, so the effect of sidewall protecting force on the slip body is not considered.
According to Eq. (3), the normal pressure of the two MCWS are

$$
\begin{aligned}
& P_{w 1}=\left(P_{1}+G^{\prime} \cos \zeta\right) v /(1-v), \\
& P_{w 2}=\left(P_{2}+G^{\prime \prime} \cos \kappa\right) v /(1-v)
\end{aligned}
$$

The sliding force $\tau$ parallel to MCWS is

$$
\begin{aligned}
& \tau_{1}=P_{1} \sin \theta+G^{\prime} \sin \omega, \\
& \tau_{2}=P_{2} \sin \theta+G^{\prime \prime} \sin \psi .
\end{aligned}
$$

The stability coefficient $K$ of the slip body can be expressed as:

$$
\begin{aligned}
K= & \left(P_{1} \sin \theta+G^{\prime} \sin \omega+P_{2} \sin \theta+G^{\prime \prime} \sin \psi\right) \\
& /\left(\mu_{1}\left(P_{1}+G^{\prime} \cos \zeta\right) v /(1-v)+\frac{1}{2} C_{1} h_{1}^{2} \cot \theta\right. \\
& \left.+\mu_{2}\left(P_{2}+G^{\prime \prime} \cos \kappa\right) v /(1-v)+\frac{1}{2} C_{2} h_{2}^{2} \cot \theta\right),
\end{aligned}
$$

where $\mu_{1}$ and $\mu_{2}$ are the sliding coefficients of MCWS bfec and MCWS $a b c d$, respectively, while $C_{1}$ and $C_{2}$ are MCWS's cohesion coefficients.

At $K>1$, the slip body will cause frictional sliding. At $K$ $\leq 1$, even if the unit has been broken, there will be no sliding instability, and no rib spalling would occur in the coal wall. Therefore, the key to limiting the frictional sliding of a slip body is to reduce the roof load and increase the sliding coefficient and cohesion of the MCWS.

\section{Numerical Simulation}

5.1. Brief Description of RFPA3D. The difference in the mechanical properties of various mineral components and defects, such as pores and fissures, determines that natural rock is a complex heterogeneous material. Tang et al. [49-51] developed an analysis system for simulating the failure process of heterogeneous rock materials-RFPA2D. This software is based on the mesoelement elastic damage constitutive relationship and combines the statistical distribution assumptions of material properties with finite element calculation methods. The maximum tensile stress criterion and the Mohr-Coulomb criterion are used to determine when these elements reach their damage thresholds. In contrast to conditional finite element numerical calculation software programs, RFPA can simulate the initial cracking, deformation localization, and fracture in the rock failure process, so that the application of finite element technology can be developed to simulate the whole process of rock failure. RFPA3D is based on the development of RFPA2D software. In this study, a numerical analysis was performed with RFPA3D to simulate the damage and fracture process of a triangular prism under the roof load and confining pressure. 


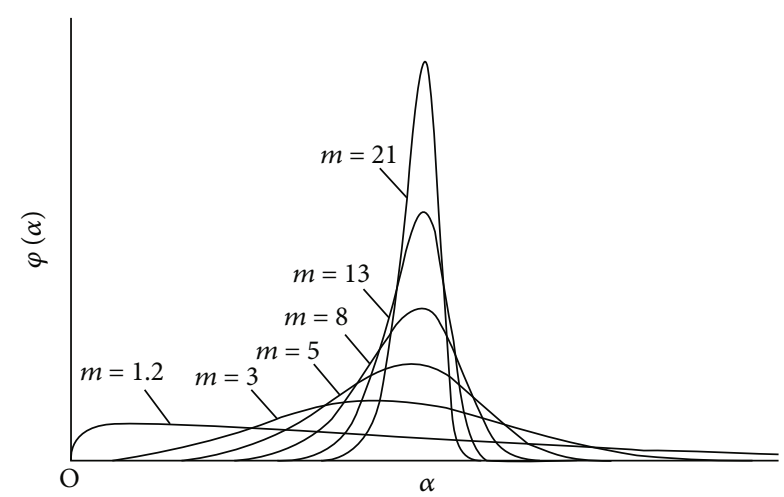

FIGURE 11: Weibull distribution for material parameters with different indices $m$.

5.2. Material Heterogeneity Description. Weibull first proposed a method to describe the heterogeneity of materials using statistical mathematics. The Weibull theory states that it is impossible to accurately measure the strength of the mesoscopic element at the time of failure, but rather, the probability of failure at a given stress level can be defined. RFPA3D assumes that the distribution of the mesoscopic elements' mechanical properties is statistical and introduces the Weibull distribution function to describe the statistical distribution density of the mechanical properties of the mesoscopic element:

$$
\varphi(\partial)=\frac{m}{\partial_{0}} \cdot\left(\frac{\partial}{\partial_{0}}\right)^{m-1} \cdot e^{-\left(\frac{\partial}{\partial_{0}}\right)^{m}}
$$

where $\partial$ is the mechanical parameter (strength, elastic modulus, etc.) of the rock mesoscopic elements, $\partial_{0}$ is its average value, and $m$ is the uniformity coefficient, which reflects the uniformity of the rock medium. Figure 11 shows the statistical distribution of the mechanical properties of the mesoscopic elements with different uniformity coefficients. Tang et al. [50, 52] have a detailed introduction on the effect of homogeneity on the macroscopic response of a sample.

5.3. The Constitutive Relationship of the Mesoscopic Element. It is widely recognized that stress in a rock body induces microcracks that propagate throughout the internal rock structure. These microcracks are caused by nonplastic deformation and contribute to the nonlinearity of the stress-strain curve. This also illustrates the rock fracture mechanism from the mesostructural standpoint. Therefore, it is reasonable to use elastic damage mechanics' constitutive relationship to describe the mechanical properties of mesoscopic elements of the rock body. Furthermore, according to the strain equivalent hypothesis, the strain caused by the stress $\sigma$ acting on the damaged material is equivalent to the strain caused by the effective stress $\tilde{\sigma}$ acting on the intact material:

$$
\left\{\begin{array}{l}
\varepsilon=\frac{\sigma}{E}=\frac{\tilde{\sigma}}{E_{0}}=\frac{\sigma}{E_{0}(1-D)}, \\
\sigma=E_{0}(1-D) \varepsilon
\end{array}\right.
$$

where $E_{0}$ and $E$ are the elastic moduli before and after damage, respectively, and $D$ is the damage variable. $D=0$ repre-

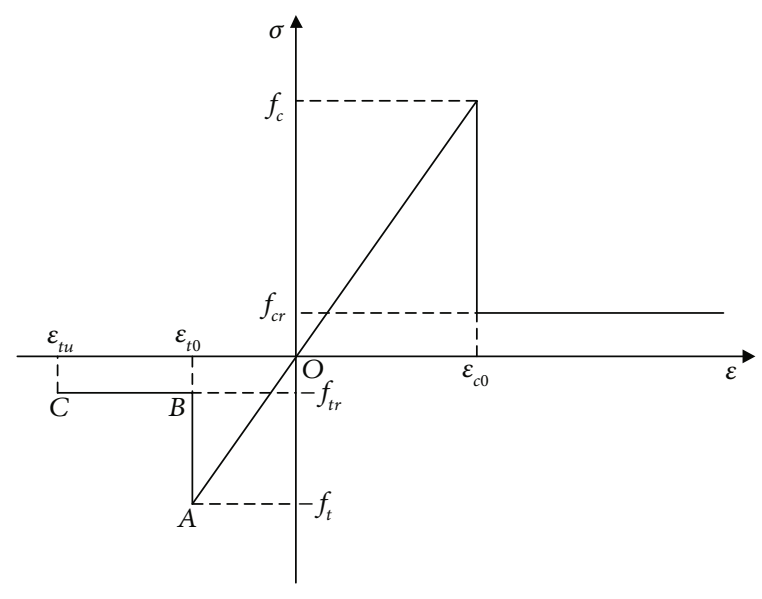

FIgURE 12: Mechanical behavior model of a mesoscopic element under uniaxial loading.

sents a nondamaged state, $D=1$ represents a complete loss of bearing capacity, and $0<D<1$ corresponds to various degrees of damage. In the initial state, the mesoscopic elements are all elastic, and their mechanical properties are expressed by their elastic moduli and breaking ratios. With a change in external conditions, the stress or strain state of the mesoscopic elements changes and is calculated by the elastic finite element program. Each element has a damage threshold where the coal body will be damaged beyond this point. Figure 12 shows the constitutive relationship of elastic damage of an element under the uniaxial stress state. Based on this, the constitutive relationship is extended to the three-dimensional stress state.

In the uniaxial tension state, the constitutive relationship of the mesoscopic element's elastic damage is shown in the left section of the coordinate axis in Figure 12. The expression of the damage variable is

$$
D= \begin{cases}0 & \varepsilon_{t 0} \leq \varepsilon \leq 0 \\ 1 \frac{f_{t r}}{E_{0} \varepsilon} & \varepsilon_{t u} \leq \varepsilon \leq \varepsilon_{t 0} \\ 1 & \varepsilon \leq \varepsilon_{t u}\end{cases}
$$

where $f_{t r}$ is the residual tensile strength of the element, $\varepsilon_{t 0}$ is the tensile strain corresponding to the elastic limit, which is the tensile damage strain threshold, and $\varepsilon_{t u}$ is the ultimate tensile strain of the element when the uniaxial tensile strain reaches the limit. When the tensile strain is reached, the element is completely damaged and reaches a fractured state, i.e., $D=1$. When the element is in a three-dimensional stress state and assuming that the damage is still isotropic, the equivalent strain $\tilde{\varepsilon}$ is used to replace the tensile strain $\varepsilon$ in Eq. (28). The equivalent strain is derived from the following relationship: $\tilde{\varepsilon}=\sqrt{\left\langle-\varepsilon_{1}\right\rangle^{2}+\left\langle-\varepsilon_{2}\right\rangle^{2}+\left\langle-\varepsilon_{3}\right\rangle^{2}}$, where \langle\rangle is a function defined as follows:

$$
\langle x\rangle\left\{\begin{array}{ll}
x & x \geq 0 \\
0 & x<0
\end{array} .\right.
$$




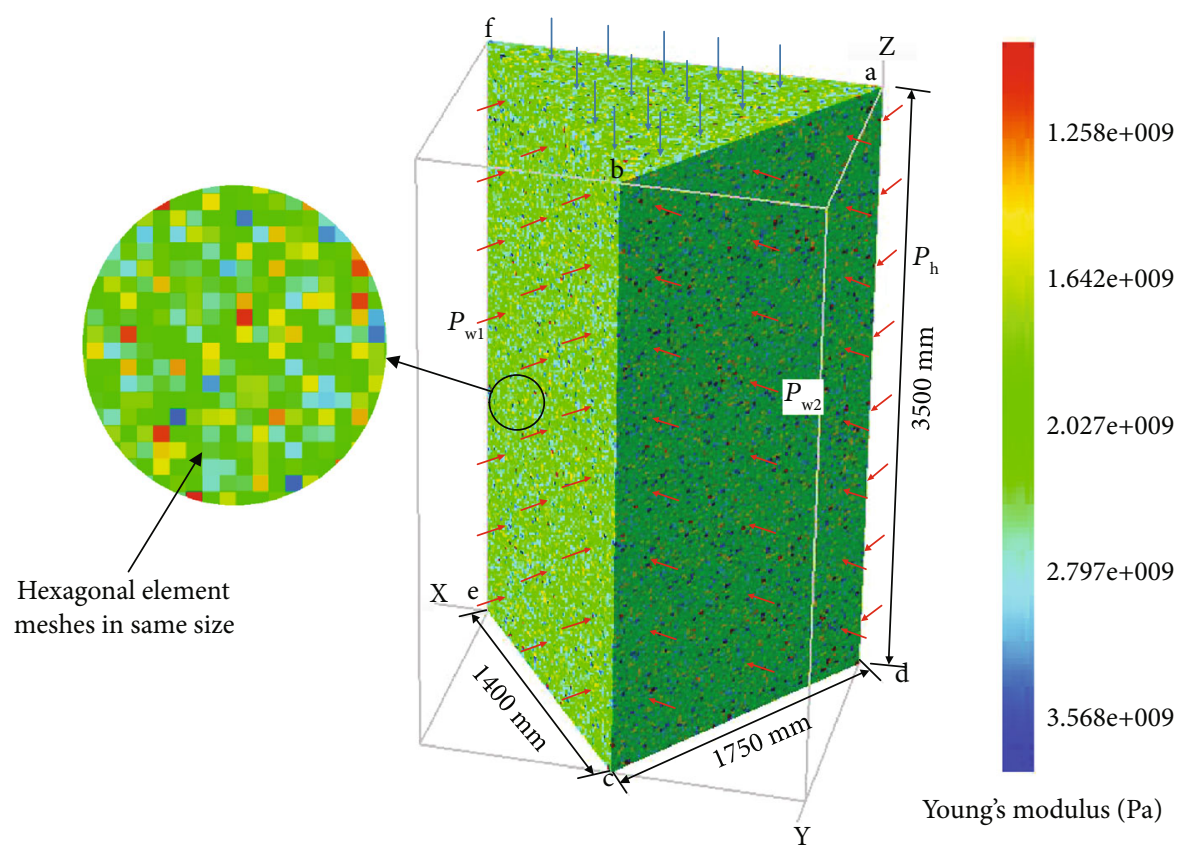

FIgURE 13: Triangular prism numerical model using the RFPA3D code.

The Mohr-Coulomb criterion is used as the damage threshold criterion when the shear damage of a mesoscopic element is caused by uniaxial compression or shear stress:

$$
F=\sigma_{1}-\frac{1+\sin \phi}{1-\sin \phi} \sigma_{3} \geq f_{c}
$$

where $\phi$ is the internal friction angle of the mesoscopic element, $f_{c}$ is the uniaxial compressive strength of the mesoscopic element, while $\sigma_{1}$ and $\sigma_{3}$ are the maximum and minimum principal stresses, respectively. In compliance with the constitutive relationship of the element's uniaxial tensile stress, its elastic damage constitutive relationship under the uniaxial compression stress of the element is shown on the right side of the coordinate axis in Figure 12. The damage variables are

$$
D=\left\{\begin{array}{ll}
0 & \varepsilon \leq \varepsilon_{c 0} \\
1-\frac{f_{c r}}{E_{0} \varepsilon} & \varepsilon_{c 0} \leq \varepsilon
\end{array},\right.
$$

where $f_{c r}$ is the compressive residual strength of the element, and $\varepsilon_{c 0}$ is the maximum compressive strain.

$$
\varepsilon_{c 0}=\frac{1}{E_{0}}\left[f_{c}+\frac{1+\sin \phi}{1-\sin \phi} \sigma_{3}-\mu\left(\sigma_{1}+\sigma_{2}\right)\right],
$$

where $\sigma_{2}$ is the intermediate principal stress and $\mu$ is Poisson's ratio. The constitutive relationship in the state of onedimensional compressive stress is extended to a threedimensional one. When the element has the triaxial stress state and satisfies the Mohr-Coulomb criterion, the maximum compressive principal strain $\varepsilon_{1}$ is used to replace the uniaxial compressive strain in Eq. (31), and $\varepsilon_{c 0}$ is derived via Eq. (32). The expression of the damage variable takes the following form:

$$
D=\left\{\begin{array}{ll}
0 & \varepsilon_{1} \leq \varepsilon_{c 0} \\
1-\frac{f_{c r}}{E_{0} \varepsilon} & \varepsilon_{c 0} \leq \varepsilon_{1}
\end{array} .\right.
$$

The RFPA3D analysis system adopts the assumption that the damaged element still has a specific stiffness and bearing capacity. Only the maximum principal tensile strain of the element reaches the ultimate tensile strain, and at $D=1$, the element is considered to be completely fractured. Notably, the treatment of cracks in the RFPA3D system is not to remove the primitive from the model but to replace the original solid primitive with a very low elastic modulus. Moreover, due to the extremely low elastic modulus of the new primitives, solid media's behavior can be approximated as nonexistent. In this way, without changing the mathematical structure, the model can reflect the change in physical characteristics caused by the primitives' rupture in terms of the overall characteristics.

5.4. Mechanical Model and Parameters. Based on the physical model of the triangular prism unit of a coal wall, the corresponding numerical model is constructed using the RFPA3D. The dimensions of the triangular prism abfdce model are shown in Figure 13. As the triangular prism has an arbitrary shape in the theoretical model, there is no special requirement for the model size. In this simulation, the model's height of $3500 \mathrm{~mm}$ is consistent with the site cutting height. The lengths of $c d$ and $c e$ sides are set as 1750 and $1400 \mathrm{~mm}$, respectively. The model contains 392,000 hexahedrons of 
TABLE 2: Material properties of a triangular prism for the numerical model.

\begin{tabular}{lc}
\hline Parameter & Value \\
\hline Homogeneity index $m$ & 5 \\
Average elastic modulus/GPa & 2.43 \\
Poisson's ratio & 0.31 \\
Mean of uniaxial compressive strength/MPa & 4.2 \\
Compressive-to-tensile strength ratio & 12 \\
Residual coefficient & 0.2 \\
\hline
\end{tabular}

the same size. The elastic modulus and uniaxial compressive strength of the mesoscopic element are set via the Weibull distribution based on Eq. (26). The bottom surface dec is fixed, while the top surface $a f b$ is subjected to a displacement load (an $8 \mathrm{~mm}$ increment per step). Surfaces $b f e c$ and $a b c d$ are subjected to constant normal stress to simulate the confining pressure applied by the surrounding elements on the triangular prism. The initial vertical stress of 11224 working face is about $17.5 \mathrm{MPa}$. The peak abutment stress measured by five coal stress detectors ahead of the working face is about $22.2 \sim 26.8 \mathrm{MPa}$, and the distance from the coal wall is $9.6 \sim 12 \mathrm{~m}$. Monitoring data show that the vertical pressure at $6 \mathrm{~m}$ from the coal wall is $7.6 \mathrm{MPa}$. As the coal body, Poisson's ratio is 0.31 , from Eq. (3), the confining pressure applied to bfec and abcd surfaces is $3.4 \mathrm{MPa}$. Surface afed is subjected to a constant normal stress of $0.2 \mathrm{MPa}$, which simulates the confining pressure on the coal wall applied by the hydraulic support guard plate. The material parameters of the triangular prism model are listed in Table 2.

5.5. Numerical Results. In calculations, the finite element degradation was simulated according to the statistical damage constitutive model described in subsection 5.1. The stress in each element was iteratively calculated at a certain loading step via the current boundary conditions, and the shift to the next loading step occurred only after the damage saturation (when no more damage was generated). During the top displacement application, the model lost its bearing capacity at step 49.

Figures 14 and 15 illustrate the failure process of the model on both $a b c d$ and $b f e c$ surfaces, respectively. For brevity sake, only a few typical details of the mesoscopic failure process in the triangular prism are shown for several selected loading stages. Here, the elastic modulus, position, acoustic emission energy level, and the maximum shear stress evolution are shown separately. The maximum shear stress and elastic modulus colors indicate their relative magnitude at a certain loading step. In acoustic emission, the center position of the sphere represents the location of elastic strain energy release, and the diameter represents the relative magnitude of energy. The blue spheres represent the acoustic emission generated during a certain loading step, and the red ones represent the accumulation at all previous steps. Both at step 8 and step 22, the triangular prism was at the stage of elastic deformation. At calculation step 8, the distribution of the elastic modulus was almost the same as before loading,

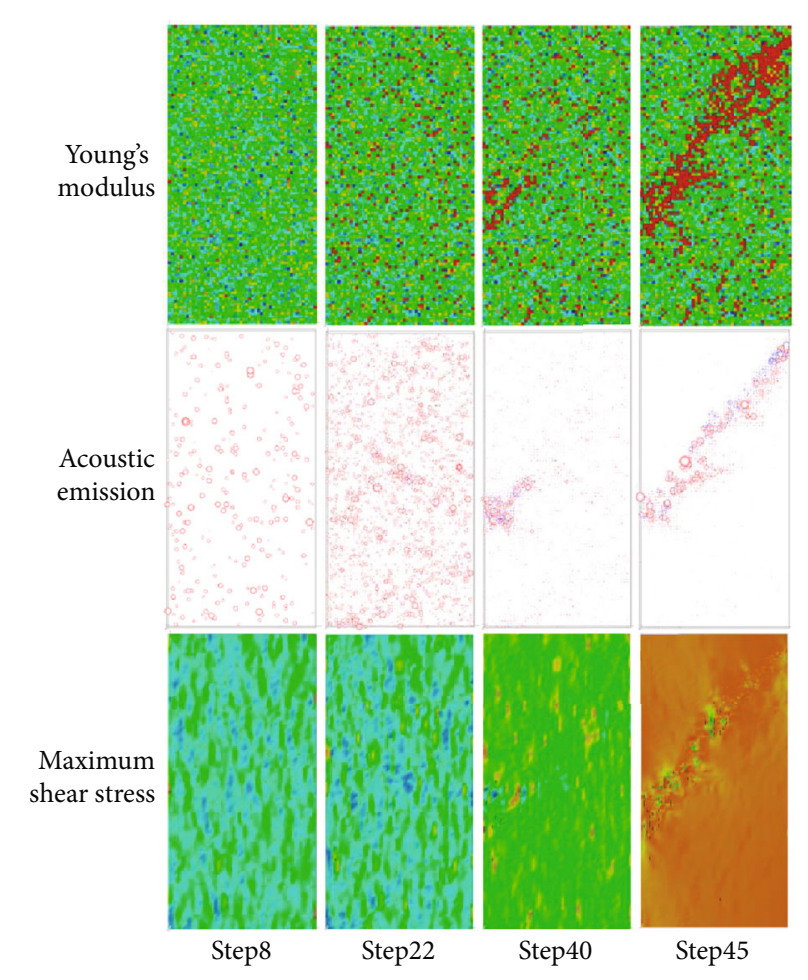

Figure 14: The continuous shear fracture process of abcd surface.

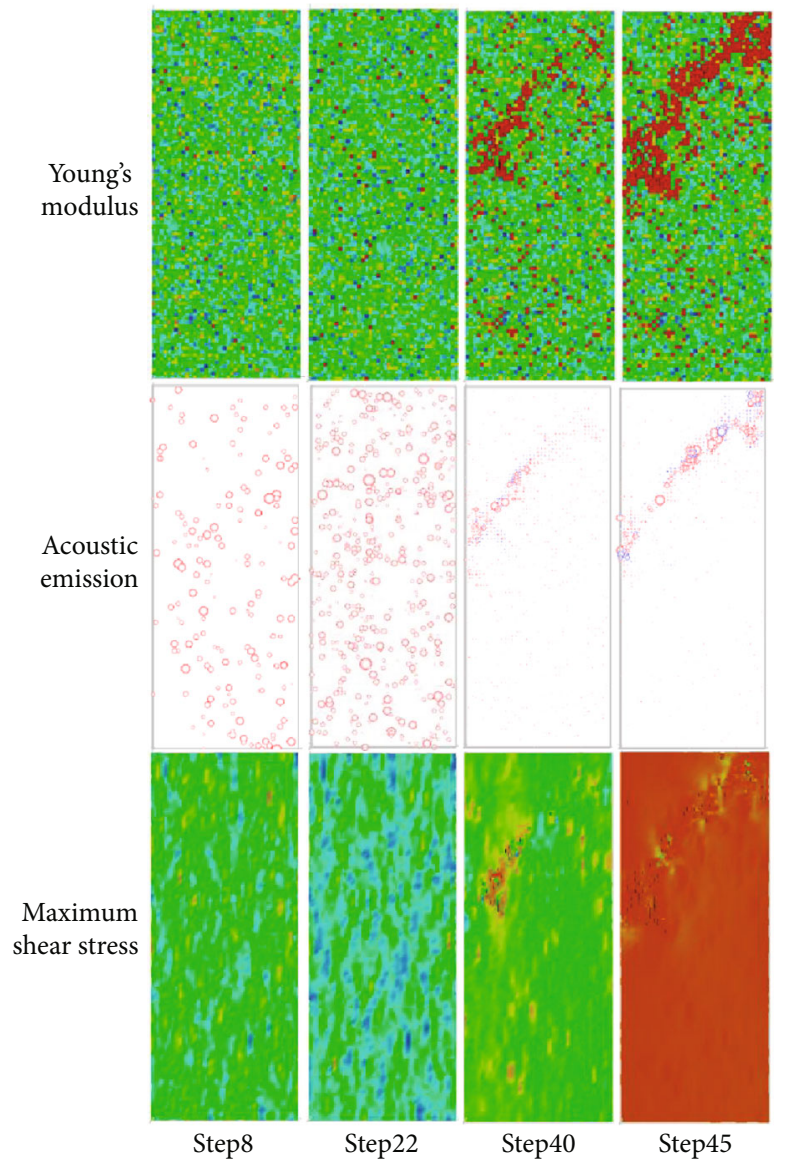

FIGURE 15: The continuous shear fracture process of $b f e c$ surface. 


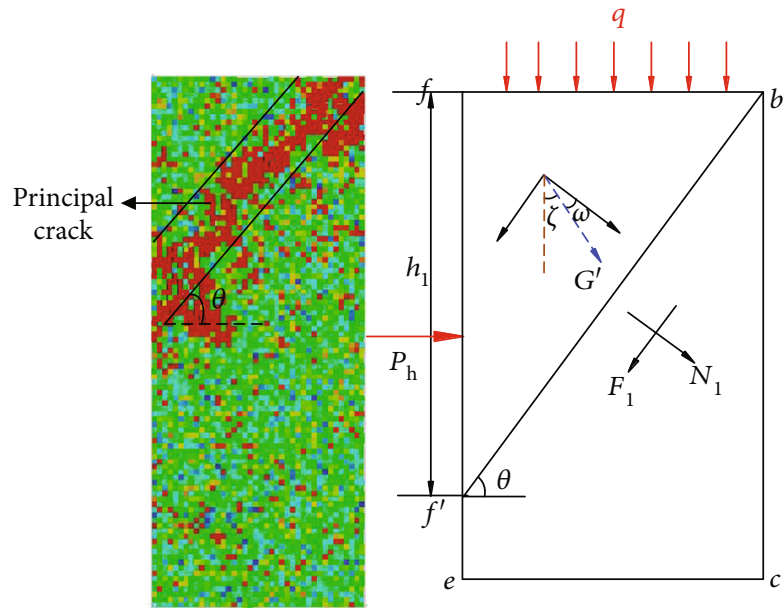

(a) The bfec surface

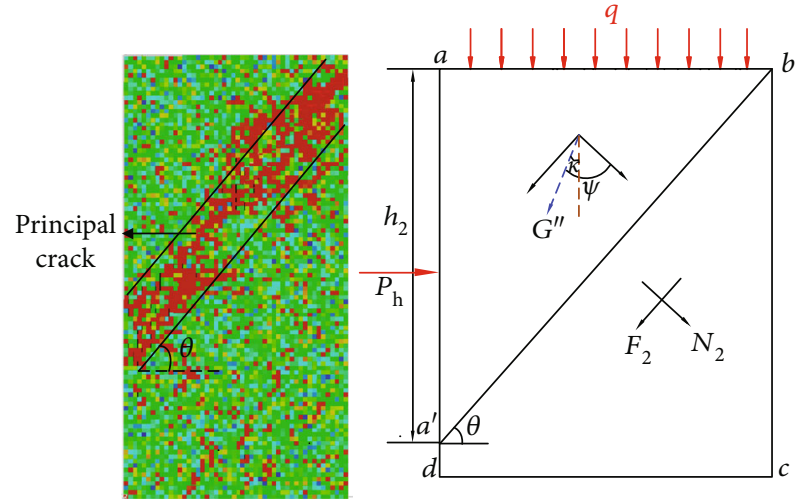

(b) The abcd surface

FIGURE 16: Comparison of fracture patterns predicted by the numerical and physical models.

indicating a zero dielectric unit damage. Therefore, only a few smaller acoustic emission sources with even energy levels were uniformly distributed in the model. The maximum shear stress distribution at this step was also relatively evenly distributed. With the axial displacement increased to step 22, numerous acoustic emission events caused by the release of elastic strain energy appeared in the two surfaces, indicating that many elements were close to being damaged. However, at this step, the distribution of maximum shear stresses was still uniform, and there was no indication of nucleation sites for the initiation and propagation of large cracks. At loading step 40, the two surfaces began to show a preliminary shear nucleation zone, which was caused by the unevenness of the unit. Macrocracks (depicted by red areas) appeared in the elastic modulus graph. A large number of acoustic emission events clustered around the shear nucleation zone, and macrofracture began to occur. At this time, the accumulated acoustic emissions in other areas of the surfaces were no longer displayed due to the relatively small magnitude of energy. Meanwhile, the maximum shear stress of the mesoscopic elements around the shear nucleation zone on the surfaces was higher than that of other areas. When the axial displacement continued to rise until step 45 , the scattered cracks in the shear nucleation zone gradually expanded, coalesced, and penetrated, leading to a distinct shear band. At the same time, continuous macroscopic cracks were formed across the shear band both on abcd and $b f e c$ surfaces. The acoustic emission resource locations were more concentrated along the shear band and associated crack. At loading step 45, the triangular prism lost its bearing capacity, and only a small residual strength remained.

5.6. Comparative Analysis of Fracture Patterns. It can be seen from the numerical results that when the soft triangular prism is loaded axially by variable confining pressure, the model will undergo shear fracture. The ultimate failure location is in the middle-upper part of the triangular prism. On both side surfaces loaded with a larger confining pressure, there is a separation through shear band, and both shear bands have the same fracture angle $\theta$ and intersection point $b$. The sliding body formed by the failure will slip across the surface, which has the minimum confining pressure. It can be seen from Figure 16 that the fracture mode of the numerical model is in good agreement with the instability mode of the physical model using the Mohr-Coulomb criterion to analyze the failure process of the coal wall unit. Therefore, the physical model proposed in this paper is suitable for the study of rib spalling of large cutting height soft coal face in protected seam mining.

\section{Conclusions}

The results obtained make it possible to draw the following conclusions:

(1) In coal mines with a large cutting height of soft coal, after the lower protective layer is mined, the upper portion of the working face forms an intricate spatial fracture pattern, which significantly differs from that of a traditional coal wall. Structural planes across the coal seam are observed in the remnants of rib spalling

(2) The physical simulation of the case study (the Paner Coal Mine, located in the Huainan mine area, China) shows that after mining of the 1223 working face, the fractured zone extended throughout SKS1 and 2 and ceased at the base of SKS3. Also, the remote protected layer was in the bending-and-sinking zone, and a large number of randomly distributed normal joint fractures appeared. Based on the analysis of the ultimate deflection of the thin plate model, a theoretical calculation model for the three overlying zones of influence was proposed, and the fracture expansion coefficient of the measured rock strata was used to calculate the fracture zone height. These measurements were consistent with the physical simulation results. Furthermore, through borehole monitoring, forward fractures of boreholes were observed in the 
vicinity of the protected layer, and no separation was revealed, indicating that SKS3 did not break and the disturbed rock strata in the boreholes were located entirely in the bending zone

(3) Based on the characteristics affected by the disturbance and the form of rib spalling, a spatial physical-mechanical model of the protected coal wall was established, and the shear failure criterion of the triangular prism formed by the division of the MCWS was proposed. The stress state analysis revealed that damage to a coal wall was related to the roof load, coal cohesion, coal internal friction angle, protection force, and coal seam inclination. The coal wall unit broke down to form a sliding body. The MCWS determined whether it could frictionally slip off along the fracture surface. The friction and sliding instability criterion of the sliding body featuring the slip body stability coefficient $K$ were also proposed. At $K>1$, the sliding body frictionally slides and forms a rib spalling

(4) The results obtained are considered quite instrumental in the analysis of rib spalling mechanisms in soft coal faces with a large cutting height and a protective layer

\section{Data Availability}

The data used to support the findings of this study are available from the corresponding author upon request.

\section{Conflicts of Interest}

The authors declare that there is no conflict of interest regarding the publication of this paper.

\section{Acknowledgments}

This work is supported by the National Natural Science Foundation of China (No. 51634007), the Institute of Energy, Hefei Comprehensive National Science Center under Grant No. 19KZS203, the National Youth Science Foundation (No. 51904011), the Anhui Provincial Natural Science Foundation (No. 1908085QE183), the Anhui University Scientific Research Foundation (No. QN2018108), and the Open Fund of State Key Laboratory of Water Resource Protection and Utilization in Coal Mining (No. GJNY-18-73.7).

\section{References}

[1] S. Yang, J. Zhang, Y. Chen, and Z. Song, "Effect of upward angle on the drawing mechanism in longwall top-coal caving mining," International Journal of Rock Mechanics \& Mining Sciences, vol. 85, pp. 92-101, 2016.

[2] Y. J. Zhang, G. R. Feng, M. Zhang, H. R. Ren, and J. W. Bai, "Residual coal exploitation and its impact on sustainable development of the coal industry in China," Energy Policy, vol. 96, pp. 534-541, 2016.

[3] Y. Z. Shang, P. F. Hei, S. B. Lu, L. Shang, and X. F. Li, "China's energy-water nexus: assessing water conservation synergies of the total coal consumption cap strategy until 2050," Applied Energy, vol. 210, pp. 643-660, 2018.

[4] G. F. Wang, Y. X. Xu, and H. W. Ren, "Intelligent and ecological coal mining as well as clean utilization technology in China: review and prospects," International Journal of Mining Science and Technology, vol. 29, no. 2, pp. 161-169, 2019.

[5] X. Y. Li, N. Zhang, Z. Z. Xie, D. X. Liang, and Y. M. Zhao, "Study on efficient utilization technology of coal pillar based on gob-side entry driving in a coal mine with great depth and high production," Sustainability, vol. 11, no. 6, 2019.

[6] S. J. Chen, D. W. Yin, X. Y. Liu, H. L. Wang, and F. W. Cao, "Collaborative mining using different equipment for a coal seam varying in thickness in a long wall working face," International Journal of Oil, Gas and Coal Technology, vol. 13, no. 1, pp. 73-86, 2016.

[7] Y. Zhang, S. G. Cao, T. Wan, and J. J. Wang, "Field Measurement and Mechanical Analysis of Height of the Water Flowing Fracture Zone in Short-Wall Block Backfill Mining beneath the Aquifer: A case study in China," Geofluids, vol. 2018, Article ID 7873682, 12 pages, 2018.

[8] L. M. Fan, T. Li, M. X. Xiang, W. Z. He, and B. Y. Wu, "Effect of Coal Mining on Springs in the Yushenfu Mining Area of China," Geofluids, vol. 2018, 16 pages, 2018.

[9] F. P. Cui, Q. Wu, Y. H. Lin, Y. F. Zeng, and K. L. Zhang, "Damage features and formation mechanism of the strong water inrush disaster at the Daxing co mine, Guangdong Province, China," Mine Water and Environment, vol. 37, no. 2, pp. 346-350, 2018.

[10] T. Liu, B. Q. Lin, W. Yang, T. Liu, and C. Zhai, “An integrated technology for gas control and green mining in deep mines based on ultra-thin seam mining," Environmental Earth Sciences, vol. 76, no. 6, pp. 1-17, 2017.

[11] C. Zhang, S. H. Tu, M. Chen, and L. Zhang, "Pressure-relief and methane production performance of pressure relief gas extraction technology in the longwall mining," Journal of Geophysics and Engineering, vol. 14, no. 1, pp. 77-89, 2017.

[12] D. P. Edwards and W. F. Laurance, "Preventing tropical mining disasters," Science, vol. 350, no. 6267, p. 1482, 2015.

[13] X. J. Chen, L. Y. Li, L. Wang, and L. L. Qi, “The current situation and prevention and control countermeasures for typical dynamic disasters in kilometer-deep mines in China," Safety Science, vol. 115, pp. 229-236, 2019.

[14] Z. J. Wen, E. R. Xing, S. S. Shi, and Y. J. Jiang, "Overlying strata structural modeling and support applicability analysis for large mining-height stopes," Journal of Loss Prevention in the Process Industries, vol. 57, pp. 94-100, 2019.

[15] Z. Y. Song and H. Konietzky, "A particle-based numerical investigation on longwall top coal caving mining," Arabian Journal of Geosciences, vol. 12, no. 18, p. 556, 2019.

[16] Z. Y. Song, H. Konietzky, and M. Herbst, "Drawing mechanism of fractured top coal in longwall top coal caving," International Journal of Rock Mechanics \& Mining Sciences, vol. 130, p. 104329, 2020.

[17] B. X. Huang, Y. Z. Wang, and S. G. Cao, "Cavability control by hydraulic fracturing for top coal caving in hard thick coal seams," International Journal of Rock Mechanics and Mining Sciences, vol. 74, pp. 45-57, 2015.

[18] Q. S. Bai, S. H. Tu, F. T. Wang, and C. Zhang, "Field and numerical investigations of gateroad system failure induced by hard roofs in a longwall top coal caving face," International Journal of Coal Geology, vol. 173, pp. 176-199, 2017. 
[19] Z. H. Wang, J. C. Wang, and S. L. Yang, "An ultrasonic-based method for longwall top-coal cavability assessment," International Journal of Rock Mechanics \& Mining Sciences, vol. 112, pp. 209-225, 2018.

[20] Z. S. Meng, Q. L. Zeng, K. D. Gao, S. Kong, and P. Liu, "Failure analysis of super-large mining height powered support," Engineering Failure Analysis, vol. 92, pp. 378-391, 2018.

[21] T. D. Le, J. Oh, B. Hebblewhite, C. G. Zhang, and R. Mitra, “A discontinuum modelling approach for investigation of longwall top coal caving mechanisms," International Journal of Rock Mechanics \& Mining Sciences, vol. 106, pp. 84-95, 2018.

[22] L. Si, Z. B. Wang, X. H. Liu, C. Tan, and R. X. Xu, "Assessment of rib spalling hazard degree in mining face based on background subtraction algorithm and support vector machine," Current Science, vol. 116, no. 12, pp. 2001-2012, 2019.

[23] W. B. Guo, C. Y. Liu, G. W. Dong, and W. Y. Lv, "Analytical study to estimate rib spalling extent and support requirements in thick seam mining," Arabian Journal of Geosciences, vol. 12, no. 8, p. 276, 2019.

[24] Y. Yuan, S. H. Tu, X. G. Zhang, and A. X. Liu, "Mechanism and control technique of rib spalling disaster in fully-mechanized mining with large mining height in soft coal seam face," Disaster Advances, vol. 6, no. 3, pp. 92-98, 2013.

[25] Y. Yuan, S. H. Tu, X. T. Ma, L. L. Sun, and Q. S. Bai, “Coal wall stability of fully mechanized working face with great mining height in 'three soft' coal seam and its control technology," Journal of Mining \& Safety Engineering, vol. 29, no. 1, pp. 21-25, 2012.

[26] H. L. Zhang, L. G. Wang, and H. Qin, "Study of spalling mechanism and control techniques of mining roadway," Rock and Soil Mechanics, vol. 33, no. 5, pp. 1462-1466, 2012.

[27] X. W. Yin, S. H. Yan, and Y. An, "Characters of the rib spalling in fully mechanized caving face with great mining height," Journal of Mining \& Safety Engineering, vol. 25, no. 2, pp. 25, 2008.

[28] Y. Ning, "Mechanism and control technique of the rib spalling in fully mechanized mining face with great mining height," Journal of China Coal Society, vol. 34, no. 1, pp. 50-52, 2009.

[29] H. J. Hao and Y. Zhang, "Stability analysis of coal wall in fullseam cutting workface with fully-mechanized in thick seam," Journal of Liaoning Technical University, vol. 24, no. 4, pp. 489-491, 2005.

[30] J. C. Wang, "Mechanism of the rib spalling and controlling in the very soft coal seam," Journal of China Coal Society, vol. 32, no. 8, pp. 785-788, 2007.

[31] B. J. Fu, M. Tu, and M. Z. Gao, "Study on unloading instability model of working face with large mining height," Journal of Mining \& Safety Engineering, vol. 34, no. 6, pp. 1128-1133, 2017.

[32] P. J. Yang, C. Y. Liu, and F. F. Wu, "Breakage and falling of a high coal wall in a thick mined seam," Journal of China University of Mining \& Technology, vol. 41, no. 3, pp. 371-377, 2012.

[33] H. W. Wang, Y. P. Wu, P. S. Xie, S. H. Luo, and K. Z. Liu, "Coal rib stability effect of mining-thickness with large mining height of working face in steeply inclined seams," Journal of Mining \& Safety Engineering, vol. 35, no. 1, pp. 64-70, 2018.

[34] Y. P. Wu, D. Lang, and P. S. Xie, "Mechanism of disaster due to rib spalling at fully-mechanized top coal caving face in soft steeply dipping seam," Journal of China Coal Society, vol. 41, no. 8, pp. 1878-1884, 2016.
[35] Y. H. Pang and G. F. Wang, "Hydraulic support protecting board analysis based on rib spalling 'tensile-sliding' mechanical model," Journal of China Coal Society, vol. 42, no. 8, pp. 1941-1950, 2017.

[36] J. F. Liu, E. X. Tang, Y. X. Xu, and Y. L. Zhang, "Study on full process precision control technology of coal wall under large mining height intelligent mining condition," Coal Science and Technology, vol. 47, no. 10, pp. 131-135, 2019.

[37] J. C. Chang, G. X. Xie, and X. H. Zhang, "Analysis of rib spalling mechanism of fully-mechanized top-coal caving face with great mining height in extra-thick coal seam," Rock and Soil Mechanics, vol. 36, no. 3, pp. 803-808, 2015.

[38] G. F. Song, S. L. Yang, and Z. H. Wang, "Longwall face stability analysis using Ritz method and its 3D physical modelling study," Journal of China Coal Society, vol. 43, no. 8, pp. 2162-2172, 2018.

[39] K. Yang, X. Y. Kong, W. Lu, and S. Liu, "Study of strata pressure behaviors with longwall mining in large inclination and thick coal seam under closed distance mined gob," Chinese Journal of Rock Mechanics and Engineering, vol. 34, no. S2, pp. 4278-4285, 2015.

[40] M. G. Qian, X. X. Miao, and J. L. Xu, "Theoretical study of key stratum in ground control," Journal of China Coal Society, vol. 21, no. 3, pp. 2-7, 1996.

[41] Q. D. Qu, J. L. Xu, R. L. Wu, W. Qin, and G. Z. Hu, “Threezone characterisation of coupled strata and gas behaviour in multi-seam mining," International Journal of Rock Mechanics \& Mining Sciences, vol. 78, pp. 91-98, 2015.

[42] B. Ghabraie, G. Ren, and J. V. Smith, "Characterising the multi-seam subsidence due to varying mining configuration, insights from physical modelling," International Journal of Rock Mechanics \& Mining Sciences, vol. 93, pp. 269-279, 2017.

[43] J. L. Xu, W. B. Zhu, and X. Z. Wang, "New method to predict the height of fractured water-conducting zone by location of key strata," Journal of China Coal Society, vol. 37, no. 5, pp. 762-769, 2012.

[44] K. Yang, S. Liu, C. A. Tang, Z. Wei, and X. L. Chi, "Mechanism and prevention of coal seam rib spalling in remote protected layer across coal group," Journal of China Coal Society, vol. 44, no. 9, pp. 2611-2621, 2019.

[45] D. G. Zhang and Y. H. Zhou, "A theoretical analysis of FGM thin plates based on physical neutral surface," Computational Materials Science, vol. 44, no. 2, pp. 716-720, 2008.

[46] H. Shao, S. G. Jiang, L. Y. Wang, and Z. Y. Wu, "Bulking factor of the strata overlying the gob and a three-dimensional numerical simulation of the air leakage flow field," Mining Science and Technology (China), vol. 21, no. 2, pp. 261-266, 2011.

[47] H. Alehossein and B. A. Poulsen, "Stress analysis of longwall top coal caving," International Journal of Rock Mechanics \& Mining Sciences, vol. 47, no. 1, pp. 30-41, 2010.

[48] N. Bilim and I. Özkan, "Determination of the effect of roof pressure on coal hardness and excavation productivity: an example from a Çayırhan lignite mine, Ankara, Central Turkey," International Journal of Coal Geology, vol. 75, no. 2, pp. 113-118, 2008.

[49] C. A. Tang, H. Liu, P. K. K. Lee, Y. Tsui, and L. Tham, "Numerical studies of the influence of microstructure on rock failure in uniaxial compression-part I: effect of heterogeneity," International Journal of Rock Mechanics \& Mining Sciences, vol. 37, no. 4, pp. 555-569, 2000. 
[50] C. A. Tang, W. T. Yang, Y. F. Fu, and X. H. Xu, "A new approach to numerical method of modelling geological processes and rock engineering problems-continuum to discontinuum and linearity to nonlinearity," Engineering Geology, vol. 49, no. 3-4, pp. 207-214, 1998.

[51] C. A. Tang, L. G. Tham, S. H. Wang, H. Liu, and W. H. Li, "A numerical study of the influence of heterogeneity on the strength characterization of rock under uniaxial tension," Mechanics of Materials, vol. 39, no. 4, pp. 326-339, 2007.

[52] C. A. Tang, L. G. Tham, P. K. K. Lee, Y. Tsui, and H. Liu, "Numerical studies of the influence of microstructure on rock failure in uniaxial compression-part II: constraint, slenderness and size effect," International Journal of Rock Mechanics \& Mining Sciences, vol. 37, no. 4, pp. 571-583, 2000. 